\title{
The Mediating Role of Self-Efficacy in Sleep Disorder and Depressive Symptoms Among Chinese Caregivers of Stroke Inpatients: A Structural Equation Modeling Analysis
}

\author{
Longjuan Cong (iD) \\ Yanhong Ju (D) ${ }^{2}$ \\ Ling Gui (iD ${ }^{3}$ \\ Bo Zhang (D) \\ Fangyan Ding $\mathbb{B}^{3}$ \\ Changqing Zou $\mathbb{1}^{4}$ \\ 'Department of Social Medicine, College \\ of Health Management, China Medical \\ University, Shenyang, Liaoning, People's \\ Republic of China; ${ }^{2}$ Section of Statistics, \\ 4th People's Hospital of Shenyang, \\ Shenyang, Liaoning, People's Republic of \\ China; ${ }^{3}$ Department of Health Service \\ Management, College of Health \\ Management, China Medical University, \\ Shenyang, Liaoning, People's Republic of \\ China; ${ }^{4}$ School of Health Humanities, \\ China Medical University, Shenyang, \\ Liaoning, People's Republic of China
}

\begin{abstract}
Purpose: Caregivers of stroke inpatients are at high risk of sleep disorder, which may lead to depressive symptoms. Self-efficacy has always been regarded as a protective factor against psychological disorders such as depressive symptoms. This study aims to investigate the sleep disorder and depressive symptoms of caregivers of stroke inpatients in China and explore the mediating effect of self-efficacy between sleep disorder and depressive symptoms among Chinese caregivers of stroke inpatients.

Patients and Methods: In this cross-sectional study, a total of 305 caregivers who were hospitalized with stroke patients completed the PROMIS Sleep Disorder Short Form Scale, General Self-Efficacy Scale and Patient Health Questionnaire-9 in two general public hospitals in northeast and southeast China. A structural equation model with bootstrap method was performed to determine the mediation of self-efficacy between sleep disorder and depressive symptoms.

Results: Among the participants, 55.4\% of caregivers reported depressive symptoms. Sleep disorder and self-efficacy were significant predictors of depressive symptoms. The direct impact of sleep disorder on depressive symptoms was positive, and the path coefficient of sleep disorder with depressive symptoms was decreased from 0.45 to $0.38(\mathrm{P}<0.01)$ after addition of self-efficacy in the model. This indicated that self-efficacy played as mediator.

Conclusion: The caregivers of stroke inpatients were in poor physical and psychological health, and more than half of the caregivers (55.4\%) suffered from depressive symptoms. Our research revealed the mediation of self-efficacy between sleep disorder and depressive symptoms, and emphasized the importance of enhancing self-efficacy to reduce depressive symptoms among caregivers of stroke inpatients. These results demonstrate that focusing on self-efficacy interventions can enhance mental health and reduce depressive symptoms effectively.
\end{abstract}

Keywords: self-efficacy, sleep disorder, depressive symptoms, Chinese caregivers of stroke inpatients

\section{Introduction}

WHO predicted that depression will be the largest burden of disease in 2030, and the latest data showed that the current global population suffering from depression has reached 350 million. ${ }^{1}$ Depression, in addition to repeated episodes of physical symptoms such as low mood, slow thinking, and decreased volition, ${ }^{2}$ there will also be varying degrees of cognitive impairment, resulting in adverse consequences of 
social function impairment. ${ }^{3}$ Caregivers are susceptible to caregiving stress, which increases the prevalence of depression. ${ }^{4}$ Because of Chinese traditional culture and medical care system, family members provide a large amount of care and support for stroke inpatients, which exert an enormous function on supporting the process of recovery among stroke inpatients. ${ }^{5}$ This kind of caregivers with family members as the mainstay often fails to meet the needs of the caregivers due to lack of relevant professional training and knowledge. ${ }^{6}$ Stroke caregivers not only take care of the task, but also control their emotions and provide positive psychological support to patients, so that the caregivers to bear greater pressure and adversely affect their health. ${ }^{7-9}$ At the same time, the caregivers of stroke are frequently at risk of sleep disorders and developing psychological problems due to the lack of adequate rest, as well as limited social interaction, and financial difficulties. ${ }^{10}$ A study found that long-term care of patients who cannot take care of themselves was prone to social isolation, loneliness, disappointment, and other bad emotions. ${ }^{11}$ Equality theory believes that the balance of giving and giving back in the exchange process will affect people's mental health, suggesting that people are prone to psychological imbalance when facing unequal encounters. ${ }^{12}$ A large number of studies have confirmed that caregivers often have varying degrees of depressive symptoms. ${ }^{13-16}$ A recent meta-analysis showed that approximately $40 \%$ of stroke caregivers experienced symptoms of depression. ${ }^{17}$ Findings in related research that the negative mental state of the caregivers will adversely affect the quality of care, thus affecting the patient's recovery process. ${ }^{18}$ Therefore, it is necessary to examine the levels of depressive symptoms among caregivers of stroke inpatients and provide effective prevention and intervention measures to relieve depressive symptoms for the stroke caregivers.

A substantial number of studies have shown that depressive symptoms are related to sleep disorder and less perceived self-efficacy. ${ }^{19-21}$ Sleep disorder include difficulty falling asleep, prolonged sleep latency, sleep interruption and early awakening, which seriously affect the individual's mental state and emotional stability. ${ }^{22}$ Related studies have found that caregivers lack of regular rest, which has varying degrees of impact on sleep. ${ }^{10,23}$ There is a bi-directional connection between sleep disorder and depressive symptoms. ${ }^{24}$ Quite a few studies have confirmed that sleep disorders are the predisposing factors of depression and are also considered to be the prodromal symptoms of depression. ${ }^{2,25-27}$ As presented in previous studies that compared with people without sleep disorders, people with sleep disorders have twice the risk of depression. $^{28}$

Studies have found that positive psychosocial resources can mediate bad emotions, enable individuals to form positive and healthy attitudes and protect themselves from mental illness. ${ }^{29}$ First proposed by the American psychologist Albert Bandura, self-efficacy as the element of positive resources that refers to the degree of confidence that individuals can accomplish something by judging their own abilities has always been an important content in positive psychosocial resources research. ${ }^{30} \mathrm{~A}$ large number of studies have shown that self-efficacy can regulate bad emotions and improve negative psychology. This means the higher the self-efficacy, the lower the degree of depression. $^{31,32}$

Based on theoretical perspectives and experience on the relations among depressive symptoms, sleep disorder and self-efficacy, it is assumed that sleep disorder is related to depressive symptoms, and self-efficacy can mediate the relationship between them. From past surveys, it can be discovered that self-efficacy was associated positively with the psychological health of stroke caregivers. Previous studies have also separately investigated the contribution of sleep disorder and self-efficacy to depressive symptoms. Therefore, we conjecture that self-efficacy may act as an intermediary between sleep disorder and depressive symptoms. However, by now, the mediation of selfefficacy between sleep disorder and depressive symptoms has not been completely investigated in the existing literature. At the same time, the depressive symptoms of caregivers of stroke inpatients in China have not been fully explored in existing studies.

Thus, we conducted a mediation analysis to explore: (1) the demographic factors of depressive symptoms in hospitalized stroke patients in China; (2) the correlation between sleep disorder and depressive symptoms; (3) the mediating role of self-efficacy in sleep disorder and depressive symptoms.

\section{Patients and Methods Study Design and Participants}

From June to October 2019, we conducted a crosssectional survey of caregivers of stroke inpatients from two general public hospitals in northeast and southeast China through cluster sampling, the Third People's 
Hospital of Chongqing and the Liaoning Provincial Rehabilitation Medicine Center. The QR code link was published through the WeChat app to collect survey information. Each participant completed a questionnaire within 20 minutes, which included demographic data, sleep status, self-efficacy evaluation, and mental health information. In the survey, the selection criteria used included: (1) a native Chinese speaker; (2) able to understand and complete the questionnaire independently; (3) caregivers of inpatients diagnosed with stroke; (4) being the principal caregiver (the person who bore most of the responsibility for caring for the recovered). The exclusion criteria included: (1) having a history of mental or cognitive impairment; (2) having serious hearing impairment; (3) having other diseases that would stop them completing the questionnaire independently; (4) care workers or other employed staff. A total of 380 caregivers of stroke inpatients were recruited for this survey. Complete and logical questionnaires were considered valid. Finally, $305 / 380$ caregivers who met the criteria completed the valid questionnaires, resulting in an efficacious response rate of $80.26 \%$.

\section{Demographic Information of Participants}

The demographic information of stroke inpatients that were collected in this study included age, gender (male, female), education level, and monthly income. Age was classified according to the proportion. "Education level" was grouped into "high school or below" and "bachelor degree or above". "Monthly income" was categorized as " $\leq 3000$ RMB", "3001-6000 RMB", and ">6000 RMB". The general demographic data of caregivers included age, gender (male, female), education level, monthly income, other chronic comorbidity, relationship with the inpatients, and sleep duration per day. Education level, and monthly income were consistent with the classification of inpatients. "Other chronic comorbidity" was categorized as "yes" and "no". "Relationship with the inpatients" was divided into "spouse", "parents or children" and "other". "Sleep duration per day" was categorized as " $\leq 6$ hours" and ">6 hours".

\section{Measurement of Sleep Disorder}

Using the Chinese version of the PROMIS Sleep Disorder Short Form Scale for measurement, participants were required to assess the degree of sleep disorder from the past one week through conscious assessment. ${ }^{33}$ This scale has 8 items, and the testees are asked to score within a Likert 5-point frequency range, ranging from 1 ("not at all") to 5 ("very"). The original total score was obtained by summarizing the scores of each item, the range from 8 to 40 points, and then converted to $\mathrm{T}$ value according to the $\mathrm{T}$ value table, with a higher standardized $\mathrm{T}$-score showing more severe sleep disorder. ${ }^{34}$ The Cronbach's alpha was 0.929 in the current sample, which has good reliability. Previous research has good reliability and validity. $^{35}$

\section{Measurement of Self-Efficacy}

Self-efficacy was measured with General Self-Efficacy Scale, which is widely used as a measure of selfefficacy. $^{36}$ The scale has 10 items, and the testees are asked to give Likert 4 points, ranging from 1 ("completely non-conforming") to 4 ("completely conforming"). Add up the scores of all items and divide by 10 to be the standardized score, with a higher standardized score indicating stronger self-efficacy. The Cronbach's alpha was 0.927 in the current sample, which has good reliability. Previous research has good reliability and validity. ${ }^{37}$

\section{Measurement of Depressive Symptoms}

Depressive symptoms were measured using Patient Health Questionnaire-9 (PHQ-9), which is one of the tools for extensive evaluation of depression. ${ }^{38}$ This scale has 9 items, and the testees are asked to score within a Likert 4-point frequency range, ranging from 0 ("not at all") to 3 ("almost every day") to evaluate feelings in the past two weeks. The total score of the project was 0-27 points, 5-9 were divided into mild depression, 10-19 were divided into moderate depression, and 20-27 were divided into severe depression. ${ }^{39}$ In this study, the Cronbach's alpha was 0.873 , which has good reliability. Previous research has good reliability and validity. ${ }^{40}$

\section{Statistical Analysis}

All statistical analyses were performed using SPSS 25.0 and AMOS 24.0. T-tests and ANOVA were performed to compare differences in depressive symptoms among the caregiver clusters. Spearman correlation coefficient was conducted to analyze the relationship between sleep disorder, self-efficacy and depressive symptoms of caregivers of stroke inpatients. Hierarchical linear regression analyses were habituated to examine the incremental variance of the respective variables using depressive symptoms as the dependent variable and the independent variables were entered in following steps: (1) demographic characteristics 
of caregivers; (2) demographic characteristics of stroke inpatients; (3) sleep disorder; (4) self-efficacy. AMOS 24.0 was applied to construct a structural equation model with the dependent variable was depressive symptoms and the independent variable was sleep disorder, while self-efficacy was the mediator. The goodness-of-fit index was $x^{2} / \mathrm{df}<5$, CFI, GFI, AGFI, TLI $>0.90$, and RMSEA $<0.08$, indicated compliance with SEM standards. The bias-corrected nonparametric percentile Bootstrap method was performed to calculate the mediating effect of self-efficacy ( $a * b$ product) between sleep disorder and depressive symptoms. The number of bootstrap samples was set to 5000, standardized measurement bias-corrected and accelerated 95\% CI (BCa 95\% $\mathrm{CI}$ ) for each $\mathrm{a} * \mathrm{~b}$ product, the mediating effect was considered to be statistically significant if zero value does not contain from the estimated confidence interval. A two-tailed probability value of $<0.05$ was considered statistical significance.

\section{Results}

The Demographic Characteristics of the Caregivers and Stroke Inpatients

The demographic characteristics and depressive symptoms distribution of caregivers of stroke inpatients surveyed are provided in Table 1. The average age of the hospitalized stroke patients was 59 years old, $70.8 \%$ were male, and $81.6 \%$ had a high school education or below. Among the 305 stroke caregivers, the age range was 21 to 86 years old (Mean = $52.81, \mathrm{SD}=12.07)$, and nearly two-thirds $(65.6 \%)$ were women. The majority of caregivers (83.3\%) had a high school education or below. The depressive symptoms score of stroke caregivers was $6.29 \pm 5.32$ points, 169 of the 305 people were depressed, and the incidence of depressive symptoms was 55.4\%. Among them, 38.8\% were mild depression, $19.7 \%$ moderate depression, and $1 \%$ severe depression. There was no significant difference in depressive symptoms scores in

Table I Demographic Characteristics of Stroke Inpatients and Caregivers

\begin{tabular}{|c|c|c|c|c|c|c|c|c|c|c|c|c|c|}
\hline \multirow[t]{2}{*}{ Variables } & \multirow[t]{2}{*}{$\mathbf{n}$} & \multirow[t]{2}{*}{$\%$} & \multicolumn{4}{|c|}{ Depressive Symptoms } & \multirow[t]{2}{*}{ Variables } & \multirow[t]{2}{*}{$\mathbf{n}$} & \multirow[t]{2}{*}{$\%$} & \multicolumn{4}{|c|}{ Depressive Symptoms } \\
\hline & & & $\mathbf{M}$ & SD & $\mathbf{F} / \mathbf{t}$ & $\boldsymbol{P}$ & & & & $\mathbf{M}$ & SD & $\mathbf{F} / \mathbf{t}$ & $\mathbf{P}$ \\
\hline \multicolumn{7}{|c|}{ Block I Demographic Characteristics of Stroke Inpatients } & \multicolumn{7}{|c|}{ Block 2 Demographic Characteristics of Caregivers } \\
\hline Age & & & & & 0.106 & 0.113 & Age & & & & & 0.123 & 0.025 \\
\hline$\leq 60$ & 142 & 46.6 & 6.80 & 5.45 & & & $\leq 55$ & 178 & 58.4 & 5.71 & 5.24 & & \\
\hline$>60$ & 163 & 53.4 & 5.83 & 5.18 & & & $>55$ & 127 & 41.6 & 7.09 & 5.34 & & \\
\hline Gender & & & & & 0.000 & 0.127 & Gender & & & & & 1.981 & 0.001 \\
\hline Male & 216 & 70.8 & 6.58 & 5.30 & & & Male & 105 & 34.4 & 4.93 & 4.82 & & \\
\hline Female & 89 & 29.2 & 5.56 & 5.32 & & & Female & 200 & 65.6 & 7.00 & 5.44 & & \\
\hline Education level & & & & & 2.099 & 0.421 & Education level & & & & & 1.602 & 0.349 \\
\hline High school or below & 249 & 81.6 & 6.40 & 5.39 & & & High school or below & 254 & 83.3 & 6.41 & 5.43 & & \\
\hline $\begin{array}{l}\text { Bachelor degree or } \\
\text { above }\end{array}$ & 56 & 18.4 & 5.77 & 5.01 & & & $\begin{array}{l}\text { Bachelor degree or } \\
\text { above }\end{array}$ & 51 & 16.7 & 5.65 & 4.73 & & \\
\hline Monthly income (RMB) & & & & & 0.149 & 0.861 & Monthly income (RMB) & & & & & 1.903 & 0.151 \\
\hline$\leq 3000$ & 86 & 28.2 & 6.35 & 5.51 & & & $\leq 3000$ & 102 & 33.4 & 5.62 & 4.98 & & \\
\hline $300 I-6000$ & 165 & 54.1 & 6.37 & 5.32 & & & $300 I-6000$ & 165 & 54.1 & 6.83 & 5.55 & & \\
\hline$>6000$ & 54 & 17.7 & 5.93 & 5.09 & & & $>6000$ & 38 & 12.5 & 5.71 & 5.03 & & \\
\hline & & & & & & & $\begin{array}{l}\text { Other chronic } \\
\text { comorbidity }\end{array}$ & & & & & 0.245 & 0.291 \\
\hline & & & & & & & Yes & 89 & 29.2 & 6.79 & 5.37 & & \\
\hline & & & & & & & No & 216 & 70.8 & 6.07 & 5.30 & & \\
\hline & & & & & & & $\begin{array}{l}\text { Relationship with the } \\
\text { inpatients }\end{array}$ & & & & & 12.587 & 0.000 \\
\hline & & & & & & & Spouse & 128 & 42.0 & 7.73 & 5.48 & & \\
\hline & & & & & & & Parents or children & 106 & 34.8 & 6.10 & 5.35 & & \\
\hline & & & & & & & Other & 71 & 23.3 & 3.94 & 4.00 & & \\
\hline & & & & & & & $\begin{array}{l}\text { Sleep duration } \\
\text { per day(h) }\end{array}$ & & & & & 4.256 & 0.000 \\
\hline & & & & & & & $\leq 6$ & 230 & 75.4 & 6.91 & 5.52 & & \\
\hline & & & & & & & $>6$ & 75 & 24.6 & 4.36 & 4.13 & & \\
\hline
\end{tabular}

Abbreviations: $M$, mean; SD, standard deviation; $P, P$-value. 
terms of education level, monthly income, and other chronic comorbidity, but differences in depressive symptoms between caregivers of different ages, genders, relationships with inpatients, and sleep duration per day can be observed. In terms of gender, the female stroke caregivers were significantly more depressed than males $(\mathrm{P}<0.01)$. Depressive symptoms were even more pronounced when caregivers were the spouse of inpatients than in other relationships, and the difference was statistical significance $(\mathrm{P}<0.01)$. Furthermore, caregivers who sleep $\leq 6$ hours a day are more depressed than those who sleep $>6$ hours $(\mathrm{P}<0.01)$.

\section{Correlations Between Depressive Symptoms, Sleep Disorder and Self-Efficacy}

The correlations among continuous variables are shown in Table 2. It showed that there are significant correlations between sleep disorder, self-efficacy and depressive symptoms in stroke caregivers. Specifically, self-efficacy had a significantly negative correlation with sleep disorder and depressive symptoms among stroke caregivers.

\section{Regression Analysis of Sleep Disorder, Self-Efficacy, and Depressive Symptoms}

The results of the hierarchical linear regression of selfefficacy as a mediator are illustrated in Table 3. The ultimate HLR model explaining $38.2 \%$ of the variance in depressive symptoms. Sleep disorder had a significantly positive correlation with depressive symptoms, and the change in $\mathrm{R}^{2}$ showed that sleep disorder contributes $16.3 \%$ to the variance of depressive symptoms. In addition, self-efficacy had a significantly negative correlation with depressive symptoms, and the influence of sleep disorder among stroke caregivers was moderately mediated by self-efficacy. The results showed that the regression coefficient $(\beta)$ between depressive symptoms and sleep disorder attenuated from 0.453 to 0.416 after

Table 2 The Correlation Among Depressive Symptoms, Sleep Disorder and Self-Efficacy

\begin{tabular}{|l|l|l|l|l|l|}
\hline Variables & Mean & SD & I & $\mathbf{2}$ & $\mathbf{3}$ \\
\hline I. Depressive symptoms & 6.29 & 5.32 & I & & \\
2. Sleep disorder & 21.01 & 8.00 & $0.464^{\mathrm{b}}$ & $\mathrm{I}$ & \\
3. Self-efficacy & 2.71 & 0.48 & $-0.267^{\mathrm{b}}$ & $-0.206^{\mathrm{b}}$ & $\mathrm{I}$ \\
\hline
\end{tabular}

Note: ${ }^{\mathrm{b}} \mathrm{P}<0.01$.

Abbreviation: SD, standard deviation. added self-efficacy to the model $(\mathrm{P}<0.01)$. The significance of the mediation was identified by Sobel test.

\section{Mediator of Self-Efficacy Between Sleep Disorder and Depressive Symptoms}

The structural equation model had good fit with the sample indicating the direct pathway from sleep disorder to depressive symptoms and the indirect pathway mediated by self-efficacy. As shown in Figure 1, sleep disorder had a directly positive impact on depressive symptoms $(\beta=0.45, \mathrm{P}<0.01)$, and the model fitting index was better $\left(x^{2} / \mathrm{df}<5, \mathrm{P}<0.05\right.$, GFI $=0.940$, $\mathrm{AGFI}=0.908, \mathrm{CFI}=0.983$, $\mathrm{TLI}=0.976$, and $\mathrm{RMSEA}=$ 0.047). As shown in Figure 2, there was a significant and negative effect of self-efficacy on sleep disorder $(\beta=-0.29$, $\mathrm{P}<0.01)$ and depressive symptoms $(\beta=-0.13, \mathrm{P}<0.05)$, and the model has a good fit index $\left(x^{2} / \mathrm{df}<5, \mathrm{P}<0.05, \mathrm{GFI}=0.927\right.$, AGFI $=0.901$, CFI $=0.990$, TLI $=0.987$, and RMSEA $=$ 0.027). The path coefficient of sleep disorder with depressive symptoms was significantly reduced, when self-efficacy was modeled as an intermediary variable $(\beta=0.38, \mathrm{P}<0.01)$. The Bootstrap sampling time is set to 5000, the indirect effects on the standardized measurement $\left(\mathrm{a}^{*} \mathrm{~b}=0.07, \mathrm{BCa} 95 \% \mathrm{CI}\right.$ : $0.005,0.078$ ), the confidence interval does not include 0 confirming that the mediating role of self-efficacy in sleep disorder and depressive symptoms. Therefore, sleep disorder not only direct influences depressive symptoms, but also affects depressive symptoms indirectly through self-efficacy.

\section{Discussion}

This study is the first attempt to explore the mediating role of self-efficacy in sleep disorder and depressive symptoms among Chinese caregivers of stroke inpatients. The present study found that sleep disorder had the greatest negative influence on depressive symptoms among the stroke caregivers, while self-efficacy plays a mediating role in sleep disorder and depressive symptoms. This research revealed that Chinese caregivers of stroke inpatients frequently experienced depressive symptoms $(55.4 \%)$, which seems to be higher than the global prevalence of depression among stroke caregivers $(40 \%){ }^{17}$ with USA $(47.9 \%)$ and Japan $(52 \%){ }^{41,42}$ Caregivers of hospitalized stroke patients may be more susceptible to the impact of sleep disorder on mental health and the severe depressive symptoms of Chinese caregivers should be paid attention to all in China.

In this study, sleep disorder has a great effect on depressive symptoms among stroke caregivers, which was in keeping with a longitudinal epidemiology meta- 
Table 3 The Hierarchical Linear Regression Analysis of Depressive Symptoms

\begin{tabular}{|c|c|c|c|c|}
\hline & \multicolumn{4}{|c|}{ Depressive Symptoms } \\
\hline & Model (Beta) & Model 2 (Beta) & Model 3 (Beta) & Model 4 (Beta) \\
\hline \multicolumn{5}{|c|}{ Block I Demographic Characteristics of Caregivers } \\
\hline Age & -0.028 & 0.002 & 0.008 & 0.004 \\
\hline Gender & $0.144^{\mathrm{a}}$ & $0.148^{\mathrm{b}}$ & 0.100 & 0.084 \\
\hline Education level & -0.086 & -0.071 & -0.085 & -0.087 \\
\hline \multicolumn{5}{|l|}{ Monthly income (RMB) } \\
\hline $300 \mathrm{I}-6000 \mathrm{VS} \leq 3000$ & 0.089 & 0.082 & 0.097 & 0.112 \\
\hline$>6000$ VS $\leq 3000$ & $0.218^{b}$ & $0.237^{b}$ & $0.211^{\mathrm{b}}$ & $0.232^{b}$ \\
\hline Other chronic comorbidity & -0.002 & -0.010 & 0.039 & 0.041 \\
\hline \multicolumn{5}{|l|}{ Relationship with the inpatients } \\
\hline Parents or children VS Spouse & $-0.333^{b}$ & $-0.310^{\mathrm{b}}$ & $-0.272^{\mathrm{b}}$ & $-0.277^{\mathrm{b}}$ \\
\hline Other VS Spouse & -0.110 & -0.102 & -0.054 & -0.048 \\
\hline Sleep duration per day & $-0.193^{b}$ & $-0.190^{\mathrm{b}}$ & -0.019 & -0.022 \\
\hline \multicolumn{5}{|c|}{ Block 2 Demographic Characteristics of Stroke Inpatients } \\
\hline Age & & -0.102 & -0.055 & -0.037 \\
\hline Gender & & -0.021 & -0.017 & -0.027 \\
\hline Education level & & -0.016 & 0.009 & 0.025 \\
\hline \multicolumn{5}{|l|}{ Monthly income (RMB) } \\
\hline $300 \mathrm{I}-6000$ VS $\leq 3000$ & & 0.020 & 0.021 & 0.024 \\
\hline$>6000$ VS $\leq 3000$ & & -0.054 & -0.032 & -0.041 \\
\hline Block 3 Sleep Disorder & & & $0.453^{b}$ & $0.416^{\mathrm{b}}$ \\
\hline Block 4 Self-efficacy & & & & $-0.190^{\mathrm{b}}$ \\
\hline $\mathrm{R}^{2}$ & 0.173 & 0.186 & 0.349 & 0.382 \\
\hline$\Delta \mathrm{R}^{2}$ & 0.173 & 0.013 & 0.163 & 0.033 \\
\hline
\end{tabular}

Notes: ${ }^{\mathrm{a}} P<0.05$; ${ }^{\mathrm{b}} \mathrm{P}<0.01$.

Abbreviation: SD, standard deviation.

analysis study of Baglioni. ${ }^{28}$ Taking care of patients at night was the main reason for lack of sleep and poor sleep quality among caregivers. There was theorized that caregivers were worried about the night activity of the patients which will cause the subjective mental stress to continue and leading to a significant increase in sleep disorder of caregivers and affecting physical and mental health finally. ${ }^{10}$ The dysregulation model of sleep posits believes that sleep disorder adversely affect mental health by weakening emotional regulation and metamorphosing the body's circadian rhythm. ${ }^{43}$ Sleep disorder may lead to alters in sleep patterns or the development of compensatory factors, which may maintain sleep disorder and promote worse mental health. ${ }^{44}$ This result stated that when caregivers informed severe sleep disorder, they will also

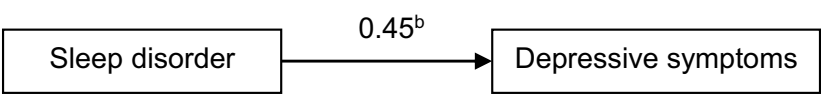

Figure I Structural equation model of sleep disorder and depressive symptoms. Note: ${ }^{b} P<0.01$. be accompanied by depressive symptoms, which was along with previous studies. ${ }^{23,45,46}$ That is, the improvement of sleep quality is important for reducing the prevalence of depressive symptoms in caregivers. Therefore, it is indispensable to adjust the quality of sleep to relieve the depressive symptoms of the caregivers of stroke.

In addition, sleep disorder was directly associated with depressive symptoms as well as indirectly influenced depressive symptoms when mediated by self-efficacy. The present study revealed that self-efficacy had a significant negative correlation with depressive

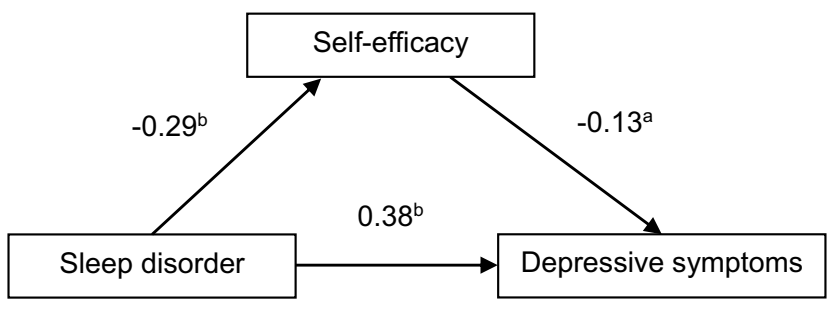

Figure 2 Structural equation model of mediating role of self-efficacy in sleep disorder and depressive symptoms.

Notes: ${ }^{\mathrm{a}} P<0.05,{ }^{\mathrm{b}} \mathrm{P}<0.01$. 
symptoms among the caregivers, which was consistent with previous studies. ${ }^{19,47}$ This may indicate that if there is more self-efficacy, caregivers can maintain mental health with higher levels of sleep quality. Self-efficacy is a protective factor, which has been consistently supported in the literature. ${ }^{48}$ It emphasizes that the individual's ability to perform a specific behavior in a specific situation determines the motivation and persistence of the individual's behavior and mainly affects the individual's health outcomes through regulation and control of behavior. ${ }^{49}$ According to Schwarzer, self-efficacy can be generalized from one to another situation and is a powerful skill, people with high self-efficacy are more optimistic about life, can take on challenging tasks, set higher goals and stick to them. ${ }^{50}$ Self-efficacy has a protective effect on one's own physical and mental health, helps eliminate bad emotions, ${ }^{51,52}$ and enhances the individual's ability to adjust and adapt to the environment, and improve the health of caregivers. ${ }^{53,54}$ However, it is worth noting that Tak YR's Cross-Lagged Model showed that self-efficacy was unable to predict the degree of subsequent depression of an individual, which may be related to the complexity of the onset of depressive symptoms. ${ }^{55}$

This study also showed that stroke caregivers who report high levels of sleep disorders were unlikely to have sufficient self-efficacy, which could lead to depressive symptoms, similar to previous studies in adolescents and young adults that sleep quality was significantly positively associated with self-efficacy. ${ }^{56,57}$ Previous studies have shown that selfefficacy, as an important variable, can reduce sleep disorder, stabilize mood regulation, and improve mental health. ${ }^{58}$ It showed that having sufficient self-efficacy can overcome the negative impact of sleep disorder on psychological health and reduce depressive symptoms. This study clarified the mediating effect of self-efficacy between sleep disorder and depressive symptoms, and become a positive resource for caregivers to reduce depressive symptoms. This research emphasizes the need to develop self-efficacy abilities-for better reduce sleep disorder in order to improve psychological health and well-being.

In summary, our study found that caregivers of Chinese hospitalized stroke patients had serious mental health problems. It revealed that self-efficacy acts as an intermediary between sleep disorder and depressive symptoms in caregivers of hospitalized stroke patients, and some preliminary recommendations could be drawn. Self-efficacy, as a changeable factor, should be improved through effective interventions with caregivers to cope with mental health problems. In the past, various forms of educational intervention programs based on groups or individuals have been successfully explored through techniques and tools. ${ }^{59,60}$ Specifically, four main strategies have been proposed in clinical practice: (1) identify and promote the skill mastery of caregivers; (2) reinterpret the symptoms; (3) modeling; (4) conduct social persuasion. $^{61}$ Hospitals or health-care departments should consider individual, group and/or family counseling/psychotherapy or related methods, and actively carry out self-efficacy enhancement interventions to enhance the mental health and well-being of caregivers.

However, there are several limitations in the current research. First, the causal relationships between sleep disorder, self-efficacy, and depressive symptoms cannot assess through a cross-sectional design, so it is necessary to verify our findings through prospective longitudinal studies in the future. In the next part, use self-reports only as a screening tool to provide identification clues and intervention recommendations. Finally, the research sample was limited to caregivers of stroke inpatients in public tertiary hospitals in northeast and southeast China, therefore, the extent to other groups need further research to confirm.

\section{Conclusion}

This research expanded the previous research by examining the influence of sleep disorder on depressive symptoms and determined the mediation of self-efficacy between sleep disorder and depressive symptoms among the stroke caregivers. This study found that $55.4 \%$ of caregivers for inpatients with stroke had depressive symptoms in China, and revealed that sleep disorder had a significantly positive correlation with depressive symptoms among caregivers. Self-efficacy as a mediator can reduce the negative impact of sleep disorder on mental health. Therefore, it is recommended to actively carry out self-efficacy enhancement interventions to reduce depressive symptoms in caregivers of stroke inpatients.

\section{Data Sharing Statement}

We cannot disclose the data because of the particularity of the survey population. If you want to obtain the data, please contact the corresponding author.

\section{Ethics Statement}

Participants fully understand the protocol of the questionnaire via mobile phone before registration, according to the principle of voluntary participation and anonymity. All Participants signed written informed consent for this study. The research 
was conducted in strict accordance with the Helsinki Declaration revised in 1989, and the Ethics Committee of China Medical University approved the protocols of this survey.

\section{Funding}

This study was supported by the Special Funding Project for Regional Collaborative Innovation in Xinjiang Uygur Autonomous Region (Grant no. 201802904); the Project funded by the Social Science Planning Fund of Liaoning Province(Grant no. L18BDJ006); the Projects entrusted and funded by the Social Science Planning Fund of Liaoning Province (Grant no. L18WTAJ006).

\section{Disclosure}

The authors report no conflicts of interest in this work.

\section{References}

1. Farah WH, Alsawas M, Mainou M, et al. Non-pharmacological treatment of depression: a systematic review and evidence map. Evid Based Med. 2016;21(6):214-221. doi:10.1136/ebmed-2016110522

2. Rakel RE. Depression. Prim Care. 1999;26(2):211-224. doi:10.1016/ S0095-4543(08)70003-4

3. Culpepper L, Lam RW, McIntyre RS. Cognitive impairment in patients with depression: awareness, assessment, and management. J Clin Psychiatry. 2017;78(9):1383-1394. doi:10.4088/JCP.tk16043ah5c

4. Grant JS, Weaver M, Elliott TR, et al. Sociodemographic, physical and psychosocial factors associated with depressive behaviour in family caregivers of stroke survivors in the acute care phase. Brain Inj. 2004;18(8):797-809. doi:10.1080/02699050410001671766

5. Qiu Y, Li S. Stroke: coping strategies and depression among Chinese caregivers of survivors during hospitalisation. J Clin Nurs. 2008;17 (12):1563-1573. doi:10.1111/j.1365-2702.2007.02156.x

6. McCarthy MJ, Lyons KS. Incongruence between stroke survivor and spouse perceptions of survivor functioning and effects on spouse mental health: a mixed-methods pilot study. Aging Ment Health. 2015;19(1):46-54. doi:10.1080/13607863.2014.913551

7. Christensen ER, Golden SL, Gesell SB. Perceived benefits of peer support groups for stroke survivors and caregivers in rural North Carolina. $N \quad C$ Med J. 2019;80(3):143-148. doi:10.18043/ ncm.80.3.143

8. Smith GC, Egbert N, Dellman-Jenkins M, et al. Reducing depression in stroke survivors and their informal caregivers: a randomized clinical trial of a web-based intervention. Rehabil Psychol. 2012;57 (3):196-206. doi:10.1037/a0029587

9. Wright LK, Hickey JV, Buckwalter KC, et al. Emotional and physical health of spouse caregivers of persons with Alzheimer's disease and stroke. $J$ Adv Nurs. 1999;30(3):552-563. doi:10.1046/j.13652648.1999.01124.x

10. Tari Moradi A, Ahadi H. Survey of depression, anxiety and physical health of caregivers to elders with aged and brain stroke. Alborz Univ Med J. 2015;3(4):199-204.

11. Arango Lasprilla JC, Moreno A, Rogers H, Francis K. The effect of dementia patient's physical, cognitive, and emotional/ behavioral problems on caregiver well-being: findings from a Spanish-speaking sample from Colombia, South America. Am J Alzheimers Dis Other Demen. 2009;24(5):384-395. doi:10.1177/1533317509341465
12. Wood AM, Joseph S. The absence of positive psychological (eudemonic) well-being as a risk factor for depression: a ten year cohort study. $J$ Affect Disord. 2010;122(3):213-217. doi:10.1016/j. jad.2009.06.032

13. Sarfo FS, Ulasavets U, Opare-Sem OK, Ovbiagele B. Telerehabilitation after stroke: an updated systematic review of the literature. J Stroke Cerebrovasc Dis. 2018;27(9):2306-2318. doi:10.1016/j.jstrokecerebrovasdis.2018.05.013

14. Hu P, Yang Q, Kong L, Hu L, Zeng L. Relationship between the anxiety/ depression and care burden of the major caregiver of stroke patients. Medicine. 2018;97(40):e12638. doi:10.1097/MD.0000000000012638

15. Ertem DH, Ilik F. Evaluation of burden and depression among caregivers of stroke patients: the role of percutaneous endoscopic gastrostomy feeding tube. Clin Nutr ESPEN. 2019;33:154-157. doi:10.1016/j.clnesp.2019.06.002

16. McCurley JL, Funes CJ, Zale EL, et al. Preventing chronic emotional distress in stroke survivors and their informal caregivers. Neurocrit Care. 2019;30(3):581-589. doi:10.1007/s12028-018-0641-6

17. Loh AZ, Tan JS, Zhang MW, et al. The global prevalence of anxiety and depressive symptoms among caregivers of stroke survivors. $\mathrm{J} \mathrm{Am} \mathrm{Med}$ Dir Assoc. 2017;18(2):111-116. doi:10.1016/j.jamda.2016.08.014

18. Koohestani H, Baghcheghi N. Burn out in caregivers of patients with stroke and its related factors. Hakim Health Sys Res. 2012;14 (4):242-248.

19. Arenella K, Steffen AM. Self-reassurance and self-efficacy for controlling upsetting thoughts predict depression, anxiety, and perceived stress in help-seeking female family caregivers. Int Psychogeriatr. 2020;32(2):229-240. doi:10.1017/S1041610219000565

20. Riemann D, Krone LB, Wulff K, et al. Sleep, insomnia, and depression. Neuropsychopharmacology. 2020;45(1):74-89. doi:10.1038/s41386019-0411-y

21. Morin V, Hozer F, Costemale-Lacoste JF. The effects of ghrelin on sleep, appetite, and memory, and its possible role in depression: a review of the literature. Encephale. 2018;44(3):256-263. doi:10.1016/j.encep.2017.10.012

22. Murphy MJ, Peterson MJ. Sleep disturbances in depression. Sleep Med Clin. 2015;10(1):17-23. doi:10.1016/j.jsmc.2014.11.009

23. Rittman M, Hinojosa MS, Findley K. Subjective sleep, burden, depression, and general health among caregivers of veterans poststroke. J Neurosci Nurs. 2009;41(1):39-52. doi:10.1097/ JNN.0b013e318193459a

24. Tsuno N, Besset A, Ritchie K. Sleep and depression. $J$ Clin Psychiatry. 2005;66(10):1254-1269. doi:10.4088/JCP.v66n1008

25. Smith K. Mental health: a world of depression. Nature. 2014;515 (7526): 181. doi:10.1038/515180a

26. Ehlers CL, Frank E, Kupfer DJ. Social zeitgebers and biological rhythms. A unified approach to understanding the etiology of depression. Arch Gen Psychiatry. 1988;45(10):948-952. doi:10.1001/ archpsyc.1988.01800340076012

27. Fava GA, Grandi S, Canestrari R, Molnar G. Prodromal symptoms in primary major depressive disorder. $J$ Affect Disord. 1990;19 (2):149-152. doi:10.1016/0165-0327(90)90020-9

28. Baglioni C, Battagliese G, Feige B. Insomnia as a predictor of depression: a meta-analytic evaluation of longitudinal epidemiological studies. J Affect Disord. 2011;135(1-3):10-19. doi:10.1016/j. jad.2011.01.011

29. Iasiello M, van Agteren J, Keyes CLM, et al. Positive mental health as a predictor of recovery from mental illness. J Affect Disord. 2019;251:227-230. doi:10.1016/j.jad.2019.03.065

30. Bandura A Social foundations for thought and action: a social cognitive theory. 1986.

31. Torrisi M, De Cola MC, Buda A, et al. Self-efficacy, poststroke depression, and rehabilitation outcomes: is there a correlation? J Stroke Cerebrovasc Dis. 2018;27(11):3208-3211. doi:10.1016/j. jstrokecerebrovasdis.2018.07.021 
32. Volz M, Voelkle MC, Werheid K. General self-efficacy as a driving factor of post-stroke depression: a longitudinal study. Neuropsychol Rehabil. 2019;29(9):1426-1438. doi:10.1080/09602011.2017.1418392

33. Yu L, Buyssem DJ, Germain A, et al. Development of short forms from the PROMIS sleep disturbance and sleep-related impairment item banks. Behav Sleep Med. 2011;10(1):6-24. doi:10.1080/ 15402002.2012 .636266

34. Deng JL. Study of Short Sleep Disorders (SDSF) in Evaluating the Effects of IMRT on Sleep in Patients with Nasopharyngeal Carcinoma [dissertation]. Nanning: Guangxi Medical University; 2017.

35. Zhang Y, Punnett L, Nannini A. Work-family conflict, sleep, and mental health of nursing assistants working in nursing homes. Workplace Health Saf. 2017;65(7):295-303. doi:10.1177/21650 79916665397

36. Luszczynska A, Scholz U, Schwarzer R. The general self-efficacy scale: multicultural validation studies. J Psychol. 2005;139 (5):439-457. doi:10.3200/JRLP.139.5.439-457

37. Deng GY. The Family Support and Self-Efficacy of Schizophrenia Patients and Their Caregivers: The Research via Projective Drawings [dissertation]. Shanghai: East China Normal University; 2017.

38. Levis B, Benedetti A, Thombs BD, et al. Accuracy of Patient Health Questionnaire-9 (PHQ-9) for screening to detect major depression: individual participant data meta-analysis. BMJ. 2019;365:11476.

39. Kroenke K, Spitzer RL, Williams JB, et al. The patient health questionnaire somatic, anxiety, and depressive symptom scales: a systematic review. Gen Hosp Psychiatry. 2010;32(4):345-359. doi:10.1016/j.genhosppsych.2010.03.006

40. Maroufizadeh S, Omani-Samani R, Almasi-Hashiani A, et al. The reliability and validity of the Patient Health Questionnaire-9 (PHQ-9) and PHQ-2 in patients with infertility. Reprod Health. 2019;16 (1):137. doi:10.1186/s12978-019-0802-x

41. McLennon SM, Bakas T, Jessup NM, et al. Task difficulty and life changes among stroke family caregivers: relationship to depressive symptoms. Arch Phys Med Rehabil. 2014;95(12):2484-2490. doi:10.1016/j.apmr.2014.04.028

42. Morimoto T, Schreiner AS, Asano H. Perceptions of burden among family caregivers of post-stroke elderly in Japan. Int J Rehabil Res. 2001;24(3):221-226. doi:10.1097/00004356-200109000-00007

43. Palagini L, Bastien CH, Marazziti D, et al. The key role of insomnia and sleep loss in the dysregulation of multiple systems involved in mood disorders: a proposed model. J Sleep Res. 2019;28(6):e12841. doi:10.1111/jsr.12841

44. McCurry SM, Song Y, Martin JL. Sleep in caregivers: what we know and what we need to learn. Curr Opin Psychiatry. 2015;28 (6):497-503. doi:10.1097/YCO.0000000000000205

45. Jackson ML, Sztendur EM, Diamond NT, et al. Sleep difficulties and the development of depression and anxiety: a longitudinal study of young Australian women. Arch Womens Ment Health. 2014;17 (3):189-198. doi:10.1007/s00737-014-0417-8

46. Chung KH, Li CY, Kuo SY, et al. Risk of psychiatric disorders in patients with chronic insomnia and sedative-hypnotic prescription: a nationwide population-based follow-up study. J Clin Sleep Med. 2015;11(5):543-551. doi:10.5664/jcsm.4700

Neuropsychiatric Disease and Treatment

\section{Publish your work in this journal}

Neuropsychiatric Disease and Treatment is an international, peerreviewed journal of clinical therapeutics and pharmacology focusing on concise rapid reporting of clinical or pre-clinical studies on a range of neuropsychiatric and neurological disorders. This journal is indexed on PubMed Central, the 'PsycINFO' database and CAS, an
47. Vloothuis JDM, Mulder M, Nijland RHM, et al. Caregiver-mediated exercises with e-health support for early supported discharge after stroke (CARE4STROKE): a randomized controlled trial. PLoS One. 2019;14(4):e0214241. doi:10.1371/journal.pone.0214241

48. Schwarzer R, Warner LM. Perceived self-efficacy and its relationship to resilience. In: Resilience in Children, Adolescents, and Adults. Springer. 2013:139-150.

49. Sheeran P, Maki A, Montanaro E, et al. The impact of changing attitudes, norms, and self-efficacy on health-related intentions and behavior: a meta-analysis. Health Psychol. 2016;35(11):1178-1188. doi: $10.1037 /$ hea0000387

50. Schwarzer R, Bandura A. Self-Efficacy: Thought Control of Action. USA: Taylor \& Francis; 1992.

51. Mikkelsen K, Stojanovska L, Polenakovic M, et al. Exercise and mental health. Maturitas. 2017;106:48-56. doi:10.1016/j.maturit as.2017.09.003

52. Jones F, Riazi A. Self-efficacy and self-management after stroke: a systematic review. Disabil Rehabil. 2011;33(10):797-810. doi:10.3109/09638288.2010.511415

53. Connell CM, Janevic MR. Effects of a telephone-based exercise intervention for dementia caregiving wives: a randomized controlled trial. J Appl Gerontol. 2009;28(2):171-194. doi:10.1177/07334 64808326951

54. Barry MM. Addressing the determinants of positive mental health: concepts, evidence and practice. Int J Ment Health Promot. 2009;11 (3):4-17. doi:10.1080/14623730.2009.9721788

55. Tak YR, Brunwasser SM, Lichtwarck-Aschoff A, et al. The prospective associations between self-efficacy and depressive symptoms from early to middle adolescence: a cross-lagged model. $J$ Youth Adolesc. 2017;46(4):744-756. doi:10.1007/s10964-016-0614-z

56. Ten Brink M, Lee HY, Manber R, et al. Stress, sleep, and coping self-efficacy in adolescents. $J$ Youth Adolesc. 2021;50(3):485-505. doi:10.1007/s10964-020-01337-4

57. Przepiorka A, Blachnio A, Siu NY. The relationships between self-efficacy, self-control, chronotype, procrastination and sleep problems in young adults. Chronobiol Int. 2019;36(8):1025-1035. doi:10.1080/07420528.2019.1607370

58. Etain B, Godin O, Boudebesse C, et al. Sleep quality and emotional reactivity cluster in bipolar disorders and impact on functioning. Eur Psychiatry. 2017;45:190-197. doi:10.1016/j.eurpsy.2017.06.013

59. Cheng ST, Au A, Losada A, et al. Psychological Interventions for dementia caregivers: what we have achieved, what we have learned. Curr Psychiatry Rep. 2019;21(7):59. doi:10.1007/s11920-019-1045-9

60. Hendrix CC, Bailey DE, Steinhauser KE, et al. Effects of enhanced caregiver training program on cancer caregiver's self-efficacy, preparedness, and psychological well-being. Support Care Cancer. 2016;24(1):327-336. doi:10.1007/s00520-015-2797-3

61. Won CW, Fitts SS, Favaro S, et al. Community-based "powerful tools" intervention enhances health of caregivers. Arch Gerontol Geriatr. 2008;46(1):89-100. doi:10.1016/j.archger.2007.02.009 is the official journal of The International Neuropsychiatric Association (INA). The manuscript management system is completely online and includes a very quick and fair peer-review system, which is all easy to use. Visit http://www.dovepress.com/testimonials.php to read real quotes from published authors. 